\title{
Lysine catabolism: flow, metabolic role and regulation
}

\author{
Ricardo Francisco Fornazier*, Ricardo Antunes Azevedo, Renato Rodrigues Ferreira \\ and Vanderlei Aparecido Varisi
}

Departamento de Genética, Escola Superior de Agricultura Luiz de Queiroz, USP, CP 83, CEP 13418-900, Piracicaba, SP, Brasil; *Corresponding author: rffornaz@esalq.usp.br

Received: 05/02/2003, Accepted: 28/02/2003

Lysine is an essential amino acid, synthesized in plants in the aspartic acid pathway. The lysine catabolism is performed by the action of two consecutive enzymes, lysine 2-oxoglutarate reductase (LOR) and saccharopine dehydrogenase (SDH). The steady state of lysine is controlled by both, synthesis and catabolism rates, with the final soluble lysine concentration in cereal seeds a direct result of these processes. In the last 40 years, the enzymes involved in lysine biosynthesis have been purified and characterized from some plant species such as carrot, maize, barley, rice, and coix. Recent reports have revealed that lysine degradation might be related to various physiological processes, for instance growth, development and response to environmental changes and stress. The understanding of the regulatory aspects of the lysine biosynthetic and catabolic pathways and manipulation of related enzymes is important for the production of high-lysine plants.

Key words: amino acids, lysine, metabolism, mutants.

Catabolismo da lisina: fluxo, papel metabólico e regulação: A lisina é um aminoácido essencial, sintetizado na via metabólica do ácido aspártico. O catabolismo da lisina é realizado pela ação das enzimas consecutivas, lisina 2-oxoglutarato redutase (LOR) e sacaropina desidrogenase (SDH). A concentração final de lisina solúvel em plantas, incluindo cereais, é controlada tanto pela taxa de síntese quanto pela de catabolismo. Nos últimos 40 anos, as enzimas envolvidas na biossíntese de lisina foram isoladas, purificadas e caracterizadas em várias espécies vegetais, incluindo cenoura, milho, cevada, arroz e coix. Relatos mais recentes revelaram que o catabolismo da lisina pode estar envolvido em vários processos fisiológicos como crescimento, desenvolvimento, resposta a mudanças e estresses ambientais. A manipulação das enzimas dessa via metabólica é imprescindível para obtenção de plantas que acumulem altos níveis de lisina solúvel, bem como um melhor conhecimento desse metabolismo.

Palavras-chave: aminoácidos, lisina, metabolismo, mutantes.

\section{Aspartic acid pathway in plants}

Plants, fungi, yeasts and most of the bacteria, usually synthesize all the 20 amino acids incorporated in a protein, while monogastric animals can only synthesize 11 of them. The nine remaining amino acids, which are termed essential, need to be provided by the diet.

The syntheses of the essential amino acids lysine, threonine, methionine and isoleucine are carried out in a complex and strongly regulated metabolic pathway, which has aspartic acid as a precursor with several enzymes being regulated by feedback inhibition (figure 1A). Since cereal seeds constitute the main source of proteins in plants and are deficient in lysine and threonine, extensive studies of this pathway have been carried out, with special attention to the potential improvement of the nutritious quality. Such studies allowed the identification of important regulatory mechanisms, showing that many enzymes are positively or negatively regulated by the end-products of the pathway (feedback) or their analogues (Heremans and Jacobs, 1994; Azevedo et al., 1997; Feller et al., 1999).

Aspartate kinase (AK), the first enzyme of the aspartic acid pathway, has been extracted, partially purified and 
well characterized in several higher plants (Azevedo et al., 1992a,b; Azevedo et al., 1997; Dey and Guha-Mukherjee, 1999). A bifunctional polypeptide with both threoninesensitive AK and homoserine dehydrogenase (HSDH) activities has been observed in some plant species (Azevedo et al., 1992b; Wilson et al., 1991; Texeira et al., 1998). The activity of the enzyme dihydrodipicolinate synthase (DHDPS), which is strongly inhibited by low concentration of lysine, has been shown to be a key regulatory point of the lysine biosynthesis branch of the pathway (Azevedo et al., 1997). Although a great deal of information is available about the lysine biosynthetic enzymes and their regulation, little is know about lysine degradation. Success in obtaining high-lysine plants for human or animal consumption relies on the full understanding of the metabolism of lysine as well as for subsequent genetic manipulation (Azevedo, 2002).

\section{The lysine catabolism in plants}

The lysine catabolism (figure 1B) in plants was initially studied in wheat, maize and barley in experiments using ${ }^{14} \mathrm{C}$-lysine, with the radioactivity being incorporated into $\alpha$-aminoadipic acid and glutamate, indicating that this amino acid is oxidatively degraded through saccharopine (Brandt, 1975; Sodek and Wilson, 1970).

Recent studies have indicated that the lysine catabolism plays an important role for lysine accumulation in plants and the control of the lysine content, particularly in seeds (Arruda et al., 2000). Initial studies with enzymes involved in the lysine degradation reinforced the main role of catabolism in the control of the soluble lysine concentration in the maize endosperm (Arruda et al., 1982; Arruda and da Silva, 1983). The amount of lysine that was shown to be translocated from other tissues to the developing endosperm, for the synthesis of storage proteins, was 2 to 3 -fold higher than what would be necessary (Arruda and da Silva, 1983). Due to excess lysine, an accumulation of lysine in the soluble form would be expected, however this does not occur, since the soluble lysine concentration was maintained at a low level during the development of the endosperm. These low lysine levels could contribute by preventing the inhibition of AK activity and facilitate the subsequent biosynthesis of methionine. These results indicated that the soluble lysine concentration is mainly controlled by the catabolic rate, instead of by the feedback inhibition of its synthesis.

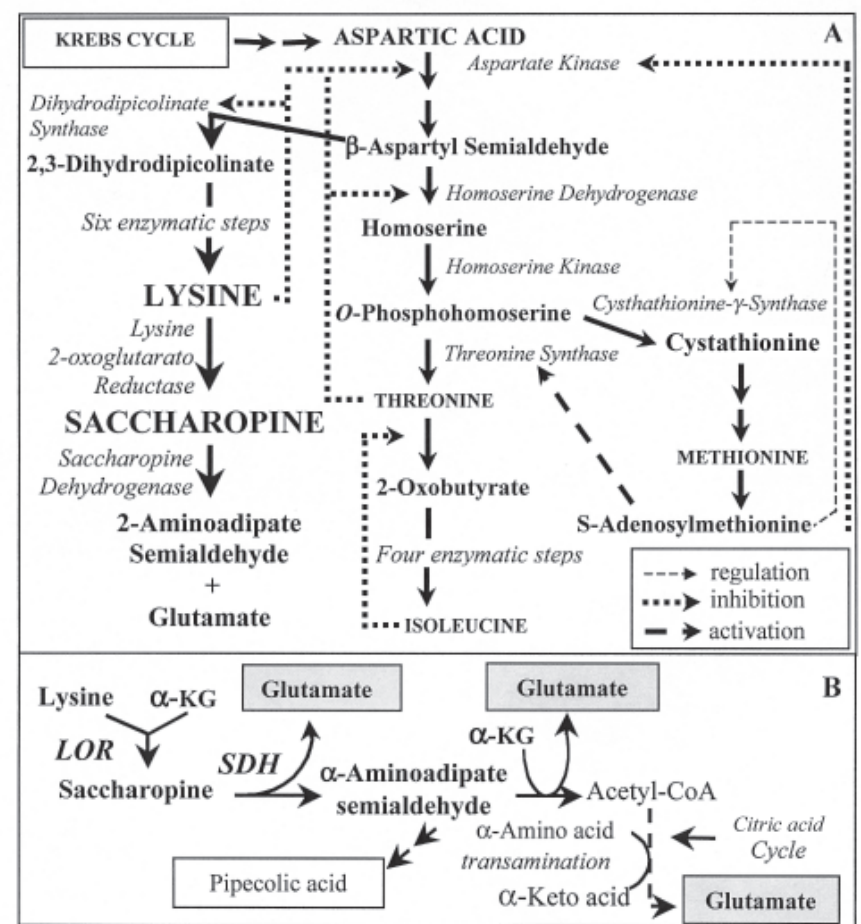

Figure 1. Aspartate metabolic pathway (A). Plant lysine catabolic pathway (B). Modified from Azevedo and Lea (2001).

\section{The purification and characterization of LOR and SDH enzymes}

Two main enzymes have been shown to be part of the lysine catabolic pathway in animals, micro-organisms and recently in plants. Lysine 2-oxoglutarate reductase (LOR; EC 1.5.1.8), (also known as lysine $\alpha$-ketoglutarate reductase, LKR) is the first enzyme of the pathway, which condenses lysine and 2-oxoglutarate to form saccharopine, which is then hydrolyzed to $\alpha$-amino adipic acid and glutamic acid in a reaction catalyzed by the enzyme saccharopine dehydrogenase (SDH; EC 1.5.1.9). The net result of these two reactions resembles a transaminase reaction in which the $\alpha$-amino group of lysine is transferred to 2-oxoglutarate to form glutamate (Azevedo et al., 1997; Azevedo and Lea, 2001). Kinetic studies have shown distinct results between maize and rice enzymes, for instance. In maize, saccharopine is a competitive inhibitor of lysine and non-competitive of 2-oxoglutarate, suggesting a mechanism were lysine first interacts with the enzyme, and afterwards with 2-oxoglutarate and $\mathrm{NADPH}$, releasing NADP ${ }^{+}$and saccharopine (BrochettoBraga et al., 1992). The opposite was observed for the rice enzymes (Gaziola et al., 1997). Both enzymes have been 
well-characterized in mammals and were shown to be part of one single bifunctional polypeptide (Markovitz and Chuang, 1987). The human bifunctional enzyme is a tetramer with a molecular mass of $460 \mathrm{kDa}$, with $115 \mathrm{kDa}$ subunits (Fjellstedt and Robinson, 1975a; Markovitz and Chuang, 1987). In fungi and yeast, the structures of LOR and SDH are comprised of monomers of $49 \mathrm{kDa}$ and 73 $\mathrm{kDa}$, encoded by the Lys 1 and Lys 9 genes, respectively (Ramos et al., 1988; Feller et al., 1999). It was only recently that these enzymes have received more attention in plants, being isolated and characterized in such species as maize, rice, soybean, Phaseolus, Arabidopsis, canola and coix. In maize, rice and coix the bifunctional enzyme LOR-SDH was shown to be endosperm-specific (Gonçalves-Butruille et al., 1996; Gaziola et al., 1997; Lugli et al., 2003; Azevedo and Lea, 2001). In maize (Gonçalves-Butruille et al., 1996), rice (Gaziola et al., 1997), soybean (Miron et al., 2000), Phaseolus vulgaris (Cunha-Lima et al., 2002) and coix (Lugli et al., 2002) the activities of LOR and SDH reside in the same bifunctional polypeptide, similar to what has been observed in mammals (Fjellstedt and Robinson, 1975a; Markovitz and Chuang, 1987). Recently, the presence of one additional monofunctional SDH enzyme was demonstrated in Arabidopsis (Tang et al., 1997) and canola (Zhu et al., 2000) which is interesting since both have already been reported as having a bifunctional LORSDH enzyme (Tang et al., 1997; Zhu et al., 2000). Furthermore, a new monofunctional LOR has now been detected in Arabidopsis (Galili et al., 2001) and in cotton (Tang et al., 2002).

The molecular mass of the LOR-SDH enzyme exhibits some variation among plant species (Azevedo and Lea, 2001). In maize, the polypeptide presents a monomeric form of $125 \mathrm{kDa}$ (Gonçalves-Butruille et al., 1996) or 140 $\mathrm{kDa}$ (Brochetto-Braga et al., 1982), when determined by SDS-PAGE or native PAGE, respectively, or $260 \mathrm{kDa}$ when determined by gel filtration, in a dimmer structure, with two $117 \mathrm{kDa}$ subunits, which constitutes the native form of the enzyme (Gonçalves-Butruille et al., 1996; Kemper et al., 1999). These subunits could be cleaved by elastase digestion into five bands ranging from $35 \mathrm{kDa}$ to $65 \mathrm{kDa}$ (Kemper et al., 1998). The separation of the five bands during the course of proteolyses could be associated with LOR and SDH activities, and the predominant 65 and 57 $\mathrm{kDa}$ bands contained the functional domains of LOR and SDH activities, respectively (Kemper et al., 1998).
In rice, the LOR-SDH protein exhibited a molecular mass of approximately $203 \mathrm{kDa}$ when determined by PAGE and gel filtration, with the presence of multimeric forms, probably dimmeric or tetrameric states $396 \mathrm{kDa}$ (Gaziola et al., 1997). In Arabidopsis, a monomeric form of 116 kDa was observed (Tang et al., 1997). In Phaseolus vulgaris, the activities of LOR-SDH also reside in a bifunctional protein and depending on the purification procedure, may elute as a monomer of $94 \mathrm{kDa}$ with $\mathrm{SDH}$ activity only, or a dimmer of $190 \mathrm{kDa}$ with both enzyme activities (Cunha-Lima et al., 2003). In soybean, monomeric forms of 100 and $123 \mathrm{kDa}$, and a $256 \mathrm{kDa}$ dimmeric form were identified (Miron et al., 2000).

\section{The regulation of LOR and SDH enzymes in plants}

Recent studies with different plant species have demonstrated that lysine may autoregulate its own catabolism in vivo, with the enzymes differentially modulated by a intracellular signaling cascade, involving mainly $\mathrm{Ca}^{2+}$, protein phosphorylation-dephosphorylation and ionic strength (Karchi et al., 1995; Miron et al., 1997; Kemper et al., 1998; Gaziola et al., 2000). Karchi et al. (1995) working with tobacco seeds observed that the activity of LOR could be stimulated by exogenous lysine and this stimulatory effect was significantly reduced when the seeds were treated with the $\mathrm{Ca}^{2+}$ chelator EGTA, an inhibitory effect that could be overwhelmed with addition of $\mathrm{Ca}^{2+}$. In maize, $\mathrm{Ca}^{2+}$ was also shown to modulate LOR activity, whereas SDH activity was not. The $\mathrm{Ca}^{2+}$ dependent LOR activity increase was also tested for inhibition by two structurally different calmodulin inhibitors, which almost completely inhibited the activity of LOR (Kemper et al., 1998). In rice, the results pertaining to the regulation were similar to those observed in maize, for both enzymes (Gaziola et al., 2000). Kemper et al. (1999) reported evidence for a $\mathrm{Ca}^{2+}$ effect on the oligomerization state of LOR-SDH from maize. $\mathrm{Ca}^{2+}$ stimulated LOR activity through the dimerization of only the LOR domain, and had no effect on the SDH activity. Figure 2A illustrates a model presented by Arruda et al. (2000).

In addition, LOR modulation has been demonstrated in maize with ionic strength, whereas the SDH activity remained unaltered (Kemper et al., 1998). Organic solvents at concentrations that lowered the water activity increased LOR activity (Kemper et al., 1998). In tobacco and 
soybean, the LOR activity was modulated with bifunctional polypeptide phosphorylation, but SDH activity was not modulated. The phosphorylation-dephosphorylation with kinase-casein II and alkaline phosphatase respectively, indicated that active LOR is a phosphoprotein with the activity being modulated by the opposite actions of the kinase and phosphatase proteins (Karchi et al., 1995; Miron et al., 1997).

In recent reports, the effects on LOR-SDH activity caused by aminoethyl-1-cysteine (AEC), a lysine analogue, and S-adenosylmethionine (SAM) have also been tested (Gaziola et al., 2000; Lugli et al., 2002). In rice, AEC was shown to be able to substitute for lysine as a substrate for LOR, but less efficiently, whereas SAM did not produce any significant changes (Gaziola et al., 1999; Gaziola et al., 2000). On the other hand, in maize, AEC was not able to substitute for lysine as a LOR substrate (Brochetto-Braga et al., 1992).

Although LOR-SDH from animals, yeast and plants have some different properties, others are common, such as optimum $\mathrm{pH}$, which are neutral for LOR (7.0 to 7.5) and basic for SDH (8.0 to 9.0) (Gonçalves-Butruille et al., 1996; Gaziola et al., 2000).

Regulatory mechanisms controlling lysine metabolism are still not fully understood and some hypothesis have been suggested. Arruda et al. (2000) and Galili et al. (2001), reported alternative hypothesis (figures $2 \mathrm{~A}$ and $2 \mathrm{~B}$ ), which consider the linkage between LOR and SDH domains that may be responsible for LOR activity modulation through protein intramolecular interactions. If such an in vivo mechanism really occurs, theoretically it would be possible to minimize the linkage through the alteration of the ionic strength in enzyme assays in vitro. Reinforcing this idea, a low LOR activity was detected in buffers without the addition of $\mathrm{NaCl}$, when compared to the LOR activity levels obtained in buffer containing $100 \mathrm{mM} \mathrm{NaCl}$. In addition, in Arabidopsis transformed with a construction, in which the interdomain and SDH domains were deleted, the LOR activity was not affected by salt concentrations (Galili et al., 2001). These results suggest that the interdomain region, as well as the SDH domain, may play a role in an interdomain interaction that affects LOR activity.

Peptides derived from the SDH domain or the interdomain were shown, in vitro, to be able to inhibit the activity of peptides derived from the LOR domain (Kemper et al., 1998). This fact suggests the existence of in vivo inhibition of the monofunctional LOR by the monofunctional SDH, although this inhibition shows less efficiency than that which occur in the case of the bifunctional LOR. On the other hand, the SDH activity does not appear to be affected by this linkage (Zhu et al., 2000). In a recent report, Zhu et al. (2002) showed that the functional interaction between the LOR and SDH domains is mediated by the linker region and not by specific affinities between these domains.

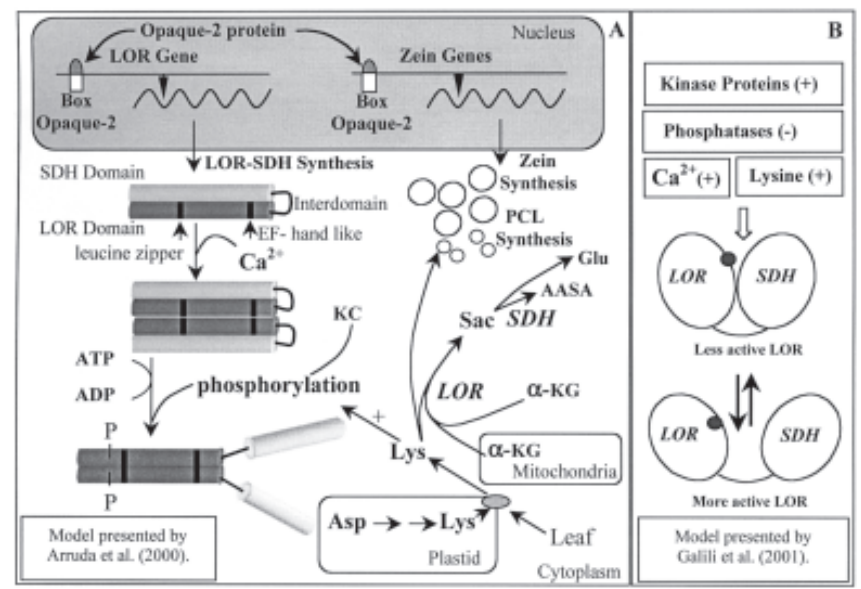

Figure 2. Model of lysine catabolism regulation in the cereal endosperm cells (A). Synthesis in plastids via the aspartate pathway and lysine translocation from vegetative tissues to the endosperm. Part of the lysine is incorporated into proteins containing lysine (PCL), however the largest storage protein fraction is the prolamins, which are deficient in lysine. In maize, the transcriptional activator opaque- 2 controls the expression of genes that encode zeins and the bifunctional LOR-SDH enzyme, which is regulated by $\mathrm{Ca} 2+$, and is involved in enzyme dimerization, and phosphorylation by casein kinase (KC) in a lysinedependent manner. As soon as the lysine concentration increases, the activity of LOR increases due to lysinedependent phosphorylation. The phosphorylation of the LOR domain could inhibit the enzyme, which would be inhibited by the SDH domain and/or interdomain region. The lysine catabolic process leads to an increase in glutamic acid and amino adipic semialdehyde (AASA). Hypothesis suggesting a conformational modulation of LOR-SDH, where the two states may to be found. Calcium, proteins kinases and phosphatases regulate the alteration between the two forms (B). 


\section{The metabolic flow through the saccharopine pathway and related implications}

In some plant tissues, such as seeds, in which the bifunctional LOR-SDH protein apparently corresponds to the majority of the total LOR activity, the lysine catabolic flow is regulated by LOR modulation via the linkage with $\mathrm{SDH}$. This may contribute to the control of lysine homeostasis through lysine-dependent stimulation of LOR activity (Karchi et al., 1994, 1995).

Dominant induction of the monofunctional LOR and SDH proteins during the abscission process and under stress conditions may maintain a high and temporary catabolic flow, leading to glutamate production. Such a flow would probably be temporary, otherwise it could lead to the depletion of the soluble-lysine pool (Galili et al., 2001). Important information concerning such an aspect has been provided by studies of canola, which demonstrated an increased SDH activity, including the monofunctional isoenzyme, under osmotic stress conditions and followed the increase in LOR activity, when the stress was more severe (Moulin et al., 2000). It has also been suggested that this linkage may influence the metabolic flow, allowing the LOR product, saccharopine, to be sent directly to the catalytic site of SDH (GonçalvesButruille et al., 1996). This hypothesis may be questionable, based on the results obtained by Falco et al. (1995), who reported saccharopine accumulation in lysine overproducing transgenic soybean seeds, maintaining some SDH activity.

Considering the regulatory mechanisms described above with the different LOR and SDH $K_{m}$ values for their substrates (Gonçalves-Butruille et al., 1996; Gaziola et al., 1997; Miron et al., 2000) and the fact that plant LOR-SDH isoenzymes have be located in the cytosol, the SDH domain may act in a physiological non-optimal $\mathrm{pH}$ for its activity (Kemper et al., 1999), suggesting that both LOR and SDH activities represent a rate-limiting step in the lysine catabolism (Miron et al., 2000) and that the metabolic flow through the saccharopine pathway is different among plant species and thus subjected to various regulatory points. This observation can be further supported by the work of Falco et al. (1995), who reported saccharopine accumulation in transgenic soybean, whereas canola exhibited accumulation of $\alpha$-amino adipate semialdehyde, another intermediate of the lysine catabolic pathway. Moreover, the identification of monofunctional SDH enzyme in a limited number of plant species (Arabidopsis, canola, and cotton) and the studies of its properties, which are similar to those determined for the bifunctional enzyme, suggests that the presence of a monofunctional SDH may provide an increase in metabolic flow, compensating for the limitation generated by the physiological cellular $\mathrm{pH}$.

The metabolic flow through the degradation pathway may be subjected to diverse regulatory mechanisms that have been studied, with special attention to the possible roles of lysine catabolism in distinct metabolic processes, such as growth, development and response to environmental changes or stress (Arruda et al., 2000; Galili et al., 2001). It may also provide further insights into the role of glutamate, which also originates from lysine catabolism (figures 1 and 3). Glutamate may be utilized as a primary precursor of the metabolite stress-related compounds such as proline, arginine, and $\gamma$-aminobutyric acid (GABA) (figure 3), which constitute stress-related signaling (Galili et al., 2001). Reinforcing the different metabolic roles it has recently been demonstrated in plants the existence of animal homologues of glutamate receptors, which appear to regulate different physiological processes (Lam et al., 1998; Brenner et al., 2000). In transgenic Arabidopsis plants, the over-expression of these glutamate receptors changed the $\mathrm{Ca}^{2+}$ balance, leading to hypersensitivity to ionic stress (Kim et al., 2001).

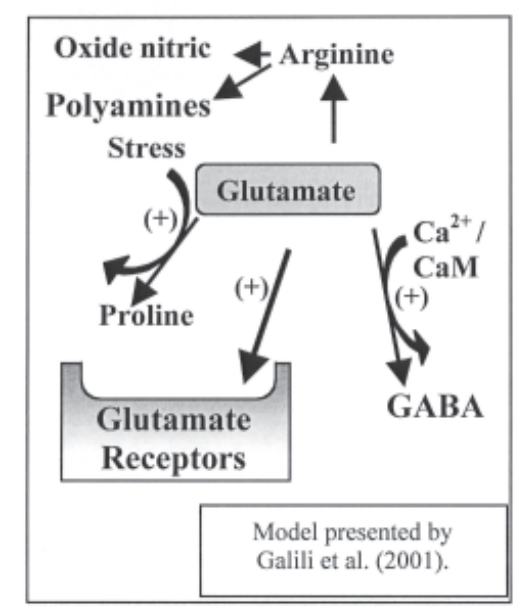

Figure 3. Conversion of glutamate to stress related compounds. The conversion of glutamate to a strong osmolite, proline, by D-pyrroline-5-carboxylate synthase; to GABA via glutamate decarboxylase calcium/calmodulin modulation; to nitric oxide (signaling molecule) via arginine. Glutamate is also a stimulator of glutamate receptors. 


\section{The expression and characteristics} of LOR and SDH genes

The LOR-SDH gene is abundantly express in floral tissues and seeds in development. The in situ mRNA hybridization suggests that the Arabidopsis LOR-SDH gene is up-regulated in ovarian tissues, embryos in development and in the outer layers of the endosperm (Tang et al., 1997). Kemper et al. (1999) have demonstrated by in situ analysis of SDH activity that the bifunctional enzyme is located in the outer layer of maize developing seeds, whereas in embryos the activity was only slightly detectable, contradicting other studies, which showed an over production of lysine in embryos and subsequent lysine catabolic products (Mazur et al., 1999). These results suggest the possibility of a putative lysine transport mechanism from embryos to the outer layers of the endosperm where lysine is then degraded (Galili et al., 2001). In developing maize seeds, the LOR-SDH gene expression is mediated by the opaque- 2 transcription factor, which also controls the expression of genes that encode zein storage proteins (Kemper et al., 1999). cDNA studies of maize (Kemper et al., 1999) and Arabidopsis (Tang et al., 1997) have shown the expression of the LOR-SDH bifunctional enzyme. One distinct and short mRNA sequence is translated from the same LOR-SDH gene that encodes the monofunctional enzyme in Arabidopsis (Tang et al., 1997). Short maize mRNA sequences have also been observed, however, they do not appear to be translated (Kemper et al., 1999).

Sequencing analysis has revealed that maize and Arabidopsis LOR-SDH genes contain the CCAAT and TATA box sequences in the promoter and in an internal region of the same gene, possibly controlling the transcripts of the bifunctional LOR-SDH and the monofunctional SDH (Arruda et al., 2000). In addition, GCN4-like sequences, which are involved in the transcription of genes related to nitrogen metabolism in yeast (Hinnebusch, 1988) and plants (Muller and Kanudsen, 1993), have been found in both the upstream and internal promoters in maize and in the internal promoters in Arabidopsis. Furthermore, sites for the linkage of opaque- 2 have also be found in the upstream and internal promoters of Arabidopsis, but only in the upstream promoter in maize. The absence of this site in the promoter of the maize LOR-SDH gene could be an explanation for the presence of the monofunctional SDH in this plant species (Arruda et al., 2000).
The LOR-SDH gene expression is not restricted to reproductive tissues, since mRNAs have been observed in canola leaves when submitted to osmotic stress (Deleu et al., 1999). Expression analyses of sequences (ESTs) related to the LOR-SDH gene in several plants suggest an abundant expression in the cell division process in various tissues, as well as in cells in the abscission zone and in tissues treated with biotic elicitors (Arruda et al., 2000).

The LOR-SDH locus, as already mentioned, is not restricted to the encoding of the bifunctional LOR-SDH and monofunctional SDH. This locus can also encode for a new monofunctional LOR as in cotton and Arabidopsis (Galili et al., 2001). In cotton, monofunctional LOR cDNAs have an identical DNA sequence to the LOR domain, suggesting that this monofunctional LOR is encoded by the some composite locus. The EST database of the abscission zone of cotton contains 1800 sequenced ESTs and presents a relatively high frequency of the monofunctional LOR.

\section{Biochemical mutants and transgenic plants for the production of high lysine plants}

Mainly in the last four decades, research groups have focused attention on understanding the biochemical and genetic controls of the aspartate pathway (Azevedo et al., 1997). The data allows researchers to induce and select for lysine and threonine overproducing plants through genetic manipulation of key points of the pathway such as catalysis by the enzymes; AK, HSDH, DHDPS, threonine synthase (TS), LOR and SDH (Heremans and Jacobs, 1994; 1995; Ravanel et al., 1998; Laber et al., 1999; Azevedo and Lea, 2001).

The development of plant tissue culture and in vitro regeneration technologies have facilitated the selection of biochemical mutants. Such mutants can be selected in cell cultures treated with mutagenic agents and selected on solid or in liquid medium amended with selective agents, such as amino acids or their analogues. The cells that eventually grow in such conditions may be mutants containing enzymes with altered regulatory characteristics (Azevedo, 2002). A similar system can also be used for embryos of seeds submitted to mutagenesis (Lea et al., 1992). Independent of the procedure utilized, the selected plants need to be genetically evaluated and biochemically characterized, as well as submitted to a complete agronomic analysis (Lea et al., 1992). 
Specifically in the case of the aspartate pathway, several mutants were selected in a large number of plant species, with the aim of obtaining cereal plants with the accumulation of lysine in seeds, which exhibited altered enzymes (Azevedo et al., 1997; Molina et al., 2001). Mutants were obtained with isoenzymes of AK that were insensitive to lysine plus threonine feedback inhibition (Bright et al., 1982; Muehlbauer et al., 1994a; Heremans and Jacobs, 1997), which exhibited an overproduction and accumulation of threonine in the leaves and in the seeds but no significant changes in the soluble lysine concentration in the seeds. These results indicated a major role of DHDPS in lysine biosynthesis, since the mutants were still sensitive to lysine feedback inhibition of the DHDPS step of the pathway, therefore driving carbon molecules to threonine biosynthesis (Azevedo and Lea, 2001). Hesse et al. (2002) suggested that after lysine biosynthesis, methionine would be considered the main route for the carbons entering the pathway, instead of threonine biosynthesis. Chiba et al. (1999) showed in Arabidopsis that the Cystathionine $\gamma$-synthase $(\mathrm{C} \gamma \mathrm{S})$ is not feedback-inhibited by end products, but its expression is regulated by methionine at the level of mRNA stability in a process that is activated by methionine or one of its catabolites. This result suggests a central role for $\mathrm{C} \gamma \mathrm{S}$ in methionine biosynthesis indicating an important flux into the aspartate pathway.

Based on the information provided by the work with the biochemical mutants and on newly developed transformation techniques, a similar strategy has been used to obtain plants that accumulate lysine in the seeds. Transgenic tobacco plants expressing a lysine-insensitive AK from E. coli exhibited similar results to those observed for the biochemical mutants, with threonine accumulation, but without changes in the soluble lysine content of the seeds (Shaul and Galili, 1992). Other transgenic plants produced with altered enzyme regulation did not result in accumulation of lysine in seeds (Shaul and Galili, 1993; Falco et al., 1995; BrinchPedersen et al., 1996).

Soluble lysine accumulation was obtained when a lysine-insensitive DHDPS from Corynebacterium was expressed in transgenic maize embryos (Falco, 2001). Moreover, the knockout of LOR-SDH by T-DNA insertion resulted in a loss of lysine and its catabolism products, but the combination of these transgenic maize plants resulted in a soluble lysine content in the seeds of about 2- to 3- fold higher than the DHDPS transgenic maize plant (Falco, 2001). Transgenic rice plants have also been obtained in order to improve the nutritional value of the seed, by elevating the lysine concentration (Lee et al., 2001). A constitutive and seed-specific expression of feedbackinsensitive maize DHDPS lead to a higher content of soluble lysine in the seeds. The higher rate of lysine biosynthesis obtained with the introduction of the altered DHDPS encoding gene also resulted in an increased rate of lysine catabolism. Even so, the over-expression of the mutant gene of DHDPS in a constitutive manner appears to overcome the lysine catabolism, thus maintaining higher lysine concentrations in the mature seeds (Lee et al., 2001). Azevedo and Lea (2001) in a recent review, suggested that lysine overproduction and accumulation in cereal seeds might be obtained by combining the genetic manipulation of the biosynthesis and lysine degradation mechanisms. Such a suggestion was supported mainly by the fact that the manipulation of enzymes involved in lysine biosynthesis did not produce lysine accumulation in cereal seeds. This could be explained by the fact that vegetables and the maize opaque-2 mutants, which exhibit higher concentration of soluble lysine in the seeds, exhibited a drastic reduction in the lysine catabolic rate in the endosperm, allowing excess lysine to be incorporated into storage proteins, as well as the accumulation in the soluble form (Azevedo and Lea, 2001; Molina et al., 2001). The maize opaque-2 mutant has been extensively studied (Gaziola et al., 1999). This mutation is characterized by an opaque phenotype with a farinaceous endosperm. The high lysine concentration observed in the endosperm is related to an increase in the concentration of soluble lysine and storage proteins with the simultaneous reduction of the prolamin fraction, which has only trace amounts of lysine (Lefèvre et al., 2002). The introduction of the opaque phenotype modifier genes allowed the production of opaque-2 maize lines with good grain productivity, that also exhibit characteristics of high lysine and tryptophan contents, but with a translucent phenotype, which have been denominated as quality protein maize - (QPM) (Vasal, 1994; Gaziola et al., 1999). QPM inbred lines have been included in breeding programs with several hybrid of QPM been produced and agronomically tested that are now commercially available (Gaziola et al., 1999).

Through transcriptome and proteome approaches, the regulatory role of the opaque- 2 gene has been confirmed, since a 3 ' restriction site was shown to be associated with 
LOR-SDH mRNA abundance (Lefèvre et al., 2002). The use of such techniques certainly will contribute significantly in the future. Azevedo et al. (1997) suggested that cereal cultivars with high lysine content seeds would probably be available in a short period of time. In a similar manner, Hesse et al. (2002) suggested possible traits to increase methionine synthesis in plants. Seed companies and research institutions have already confirmed such a possibility. Even so, additional studies will still be necessary to completely understand the regulatory aspects of lysine, threonine and methionine metabolism and how these mechanisms can be controlled.

Several informations can be obtained by the investigation of protein concentrations of the opaque and floury maize mutants, and of similar mutants of barley, sorghum and other cereal crops. It is surprising that based on the available information, and to the best of our knowledge, other cereals with high lysine mutants, similar to the opaque-2 mutants of maize, have not been utilized in research programs to study the aspartate metabolic pathway, which could further increase our understanding of lysine metabolism (Azevedo, 2002).

Acknowledgements: The authors wish to thank the Fundação de Amparo à Pesquisa do Estado de São Paulo (FAPESP) for continuous financial support, since 1993, to study the metabolism of lysine in plants.

\section{REFERENCES}

Azevedo RA, Arana JL, Arruda P (1990) Biochemical genetics of the interaction of the lysine plus threonine resistant mutant $L t r^{*} 19$ with opaque-2 maize mutant. Plant Sci. 70:81-90.

Azevedo RA, Blackwell RD, Smith RJ, Lea PJ (1992a) Three aspartate kinase isoenzymes from maize. Phytochemistry 31:3725-3730.

Azevedo RA, Smith RJ, Lea PJ (1992b) Aspartate kinase regulation in maize: evidence for co-purification of threonine-sensitive aspartate kinase and homoserine dehydrogenase. Phytochemistry 31:3731-3734.

Azevedo RA, Arruda P, Turner WL, Lea PJ (1997) The biosynthesis and metabolism of the aspartate derived amino acids in higher plants. Phytochemistry 46:395-419.

Azevedo RA, Lea PJ (2001) Lysine metabolism in higher plants. Amino Acids 20:261-279.

Azevedo RA (2002) Analysis of the aspartic acid metabolic pathway using mutant genes. Amino Acids 22:217-230.
Arruda P, Sodek L, da Silva WJ. (1982) Lysine-ketoglutarate reductase activity in developing maize endosperm. Plant Physiol. 69: 988-989.

Arruda P, da Silva WJ (1983) Lysine-ketoglutarate reductaseactivity in maize-Its possible role in lysine metabolism of developing endosperm. Phytochemistry 22:2687-2689.

Arruda P, Kemper EL, Papes F, Leite A (2000) Regulation of lysine catabolism in higher plants. Trends Plant Sci. $5: 324-330$.

Brandt AB (1975) In vivo incorporation of lysine- $\mathrm{C}^{14}$ into the endosperm proteins of wild type and high lysine barley. FEBS Lett. 52:288-291.

BrinchPedersen H, Galili G, Knudsen S, Holm PB (1996) Engineering of the aspartate family biosynthetic pathway in barley (Hordeum vulgare L.) by transformation with heterologous genes encoding feedback-insensitive aspartate kinase and dihydrodipicolinate synthase. Plant Mol. Biol. 32:611-620.

Brochetto-Braga MR, Leite A, Arruda P (1992) Partial purification and characterization of lysine-ketoglutarate reductase in normal and opaque- 2 maize endosperm. Plant Physiol. 98:1139-1147.

Chiba Y, Ishikawa M, Kijima F, Tyson RH, Kim J, Yamamoto A, Mambara E, Leustek T, Wallsgrove RM, Naito S (1999) Evidence for autoregulation of cystathionine $\gamma$-synthase mRNA stability in Arabidopsis. Science 286:1371-1374.

Cunha-Lima ST, Azevedo RA, Santoro LG, Gaziola SA, Lea PJ (2003) Isolation of the bifunctional enzyme lysine 2oxoglutarate reductase-saccharopine dehydrogenase from Phaseolus vulgaris. Amino Acids 24:179-186.

Deleu C, Coustaut M, Niogert MF, Larpher F (1999) Three new osmotic stress-regulated cDNAs identified by differential display polymerase chain reaction in rapeseed leaf discs. Plant Cell Environ. 22:979-988.

Dey M, Guha-Mukherjee S (1999) Phytochrome activation of aspartate kinase in etiolated chickpea (Cicer arietinum) seedlings. J. Plant Physiol. 154:454-458.

Falco SC, Guida T, Locke M, Mauvais J, Sanders C, Ward RT, Webber P (1995) Transgenic canola and soybean seeds with increased lysine. Biotechnology 13:577-582.

Falco SC (2001) Increasing lysine in corn. Amino Acids 21:57-58.

Feller A, Ramos F, Pierard A, Dubois E (1999) In Saccharomyces cerevisae, feedback inhibition of homocitrate synthase isoenzymes by lysine modulates the activation of LYS gene expression by Lys14p. Eur. J. Biochem. 261:163-170. 
Fjellstedt TA, Robinson JC (1975) Purification and properties of L-lysine- $\alpha$ ketoglutarate reductase from human placenta. Arch. Biochem. Biophys. 168:536-548.

Galili G, Tang G, Zhu X, Gakiere B (2001) Lysine catabolism: a stress and development super-regulated metabolic pathway. Curr. Opin. Plant Biol. 4:261-266.

Gaziola SA, Teixeira CMG, Lugli J, Sodek L, Azevedo RA (1997) The enzymology of lysine catabolism in rice seeds. Isolation, characterization, and regulatory properties of a lysine 2-oxoglutarate/saccharopine dehydrogenase bifunctional polypeptide. Eur. J. Biochem. 247:364-371.

Gaziola SA, Alessi ES, Guimarães PEO, Damerval C, Azevedo RA (1999) Quality protein maize: a biochemical study of enzymes involved in lysine metabolism. J. Agric. Food Chem. 47:1268-1275.

Gaziola SA, Sodek L, Arruda P, Lea PJ, Azevedo RA (2000) Degradation of lysine in rice seeds: Effect of calcium, ionic strength, S-adenosylmethionine and S-2-aminoethyl-Lcysteine on the lysine 2-oxoglutarate reductasesaccharopine dehydrogenase bifunctional enzyme. Physiol. Plant. 110:164-171.

Gonçalves-Butruille M, Szajner P, Torigoi E, Leite A, Arruda $P$ (1996) Purification and characterization of the bifunctional enzyme lysine-ketoglutarate reductase saccharopine dehydrogenase from maize. Plant Physiol. 110:765-771.

Heremans B, Jacobs M (1994) Selection of Arabidopsis thaliana (L.) Heynt. Mutants resistant to aspartate-derived amino acids and analogues. Plant Sci. 101:151-162.

Heremans B, Jacobs M (1995) Threonine accumulation in a mutant of Arabidopsis thaliana (L.) Heynth with an altered aspartate kinase. J. Plant Physiol. 146:249-257.

Heremans B, Jacobs M (1997) A mutant of (Arabidopsis thaliana L.) Heynth with modified control of aspartate kinase by threonine. Biochem. Genet. 35:139-153.

Hesse H, Kreft O, Maimann S, Zeh M, Willmitzer L, Hofgen $\mathrm{R}$ (2001) Approaches towards understanding methionine biosynthesis in higher plants. Amino Acids 20:281-289.

Hinnebusch AG (1988) Mechanism of gene regulation in the general control of amino acid biosynthesis in Saccharomyces cervisiae. Microbiol. Rev. 52:248-273.

Karchi H, Miron D, Benyaacov S, Galili G (1995) The lysinedependent stimulation of lysine catabolism in tobacco seed requires calcium and protein-phosphorylation. Plant Cell 7:1963-1970.

Karchi H, Shaul O, Galili G (1994) Lysine synthesis and catabolism are coordinately regulated during tobacco seed development. Proc. Natl Acad. Sci. USA 91:2577-2581.
Kemper EL, Cord-Neto G, Capella AN, Gonçalves-Butruille M, Azevedo RA, Arruda P (1998) Structure and regulation of the bifunctional enzyme lysine-ketoglutarate reductasesaccharopine dehydrogenase in maize. Eur. J. Biochem. 253:720-729.

Kemper EL, Cord-Neto G, Papes F, Martinez-Moraes KC, Leite A, Arruda P (1999) The role of opaque-2 on the control of lysine degrading activities in developing maize endosperm. Plant Cell 11:1981-1994.

Kim SA, Kwak JM, Jae SK, Wang MH, Nam HG (2001) Overexpression of the ATGluR2 gene encoding an Arabidopsis homologue of mammalian glutamate receptors impairs calcium utilization and sensitivity to ionic stress in transgenic plants. Plant Cell Physiol. 15:74-84.

Laber B, Maurer W, Hanke C, Grafe S, Ehler S, Messerschimidt A, Clausen T (1999) Characterization of recombinant Arabidopsis thaliana threonine synthase. Eur. J. Biochem. 263:212-221.

Lam HM, Chui J, Hsieh MH, Meisel L, Oliveira IC, Shin M, Coruzzi G (1998) Glutamate-receptor genes in plants. Nature 396:125-126.

Lea PJ, Blackwell RD, Azevedo RA (1992) Analysis of barley metabolism using mutant genes. In: Shewry PR (ed), Barley: genetics, biochemistry, molecular biology and biotechnology, pp.181-208. CAB International, Wallingford.

Lee SI, Kim HU, Lee YH, Suh SC, Lim YP, Lee HY, Kim HI (2001) Constitutive and seed-specific expression of a maize lysine-feedback-insensitive dihydrodipicolinate synthase gene leads to increased free lysine in rice seeds. Mol. Breed. 8:75-84.

Lefèvre A, Consoli L, Gaziola SA, Pellegrino AP, Azevedo RA, Damerval C (2002) Dissecting the opaque-2 regulatory network using transcriptome and proteome approaches along with enzyme activity measurements. Scientia Agricola 59:407-414.

Lugli J, Campbell A, Gaziola SA, Smith RJ, Lea PJ, Azevedo RA (2002) Enzymes of lysine metabolism from Coix lacryma-jobi seeds. Plant Physiol. Biochem. 40:25-32.

Markovitz PJ, Chuang, DT (1987) The bifunctional aminoadipic semialdehyde synthase in lysine degradation. J. Biol. Chem. 262:9353-9358.

Mazur B, Krebbers E, Tingey S (1999) Gene discovery and product development for grain quality traits. Science 285:372-375.

Miron D, Ben-Yaacov S, Karchi H, Galili G (1997) In vitro dephosphorylation inhibits the activity of soybean lysineoxoglutarate reductase in a lysine-regulated manner. Plant J. 12:1453-1458. 
Miron D, Ben-Yaacov S, Reches D, Schupper A, Galili G (2000) Purification and characterization of bifunctional lysine-ketoglutarate reductase/saccharopine dehydrogenase from developing soybean seeds. Plant Physiol. 123:665-663.

Molina SMG, Gaziola SA, Lea PJ, Azevedo RA (2001) Manipulating cereal crops for high lysine accumulation in seeds. Scientia Agricola 58:205-211.

Moulin M, Deleu C, Larher F (2000) L-Lysine catabolism is osmo-regulated at the level of lysine-ketoglutarate reductase and saccharopine dehydrogenase in rapeseed leaf discs. Plant Physiol. Biochem. 38:577-585.

Muehlbauer GJ, Somers DA, Matthews BJ, Gengenbach BG (1994) Molecular genetics of the maize (Zea mays L.) aspartate kinase-homoserine dehydrogenase gene family. Plant Physiol. 106:1303-1312.

Muller M, Knudsen S (1993) The nitrogen response of a barley C-hordein promoter is controlled by positive and negative regulation of the GCN4 and endosperm box. Plant J. 4:343-355.

Ravanel S, Gakiere B, Job D, Douce R (1998) The specific features of methionine biosynthesis and metabolism in plants. Proc. Natl. Acad. Sci. USA 95:7805-7812.

Shaul O, Galili G (1992) Threonine overproduction in transgenic tobacco plants expressing a mutant desensitized aspartate kinase of Escherichia coli. Plant Physiol. 100:1157-1163.

Shaul O, Galili G (1993) Concerted regulation of lysine and threonine synthesis in tobacco plants expressing bacterial feedback-insensitive aspartate kinase and dihydrodipicolinate synthase. Plant Mol. Biol. 23:759-768.

Sodek L, Wilson CM (1970) Incorporation of leucine- $\mathrm{C}^{14}$ into protein in the developing of normal and opaque-2 corn. Arch. Biochem. Biophys. 140:29-38.

Tang G, Miron D, Zhu-Shimoni JX, Galili G (1997) Regulation of lysine catabolism through lysine-oxoglutarate reductase and saccharopine dehydrogenase in Arabidopsis. Plant Cell 9:1305-1316.

Tang G, Zhu X, Gskiere B, Levanony H, Kahana A, Galili G (2002) The bifunctional $L K R / S D H$ locus of plants also encodes a highly active monofunctional lysineketoglutarate reductase using a polyadenylation signal located within an intron. Plant Physiol. 130:147-154.

Vasal SK (1994) High quality protein corn. In: Hallawer AR (ed), Specialty Corns, pp.79-120, CRC Press, Boca Raton, FL.

Wilson BJ, Gray AC, Matthews BF (1991) Bifunctional protein in carrot contains both aspartate kinase and homoserine dehydrogenase activities. Plant Physiol. 97:1323-1328.

Zhu X, Tang G, Galili G (2000) Characterization of the two saccharopine dehydrogenase isozymes of lysine catabolism encoded by the single composite AtLKR-SDH locus of Arabidopsis. Plant Physiol. 124:1363-1372.

Zhu XH, Tang GL, Galili G (2002) The activity of the Arabidopsis bifunctional lysine-ketoglutarate reductase/ saccharopine dehydrogenase enzyme of lysine catabolism is regulated by functional interaction between its two enzyme domains. J. Biol. Chem. 277:49655-49661. 